\title{
Heart rate and oxygen demand of powered exoskeleton-assisted walking in persons with paraplegia
}

\author{
Pierre Asselin, MS; ${ }^{1}$ Steven Knezevic, MS; ${ }^{1}$ Stephen Kornfeld, DO; ${ }^{1-2}$ Christopher Cirnigliaro, MS; ${ }^{1}$ Irina \\ Agranova-Breyter, PT; ${ }^{3}$ William A. Bauman, MD; ${ }^{1,4}$ Ann M. Spungen, EdD ${ }^{1,4^{*}}$ \\ ${ }^{1}$ Department of Veterans Affairs (VA) Rehabilitation Research and Development National Center of Excellence for the \\ Medical Consequences of Spinal Cord Injury, ${ }^{2}$ Spinal Cord Injury Patient Care Center, and ${ }^{3}$ Rehabilitation Medicine, \\ James J. Peters VA Medical Center, Bronx, NY; ${ }^{4}$ Departments of Medicine and Rehabilitation Medicine, Icahn School \\ of Medicine at Mount Sinai, New York, NY
}

\begin{abstract}
Historically, persons with paralysis have limited options for overground ambulation. Recently, powered exoskeletons, which are systems that translate the user's body movements to activate motors that move the lower limbs through a predetermined gait pattern, have become available. As part of an ongoing clinical study (NCT01454570), eight nonambulatory persons with paraplegia were trained to ambulate with a powered exoskeleton. Measurements of oxygen uptake $\left(\mathrm{VO}_{2}\right)$ and heart rate (HR) were recorded for 6 min each during each maneuver while sitting, standing, and walking. The average value of $\mathrm{VO}_{2}$ during walking $(11.2+/-1.7 \mathrm{~mL} / \mathrm{kg} / \mathrm{min})$ was significantly higher than for sitting and standing $(3.5+/-0.4$ and $4.3+/-0.9 \mathrm{~mL} / \mathrm{kg} / \mathrm{min}$, respectively; $p<0.001$ ). The HR response during walking was significantly greater than that of either sitting or standing $(118+/-21$ vs $70+/-10$ and $81+/-$ 12 beats per minute, respectively; $p<0.001$ ). Persons with paraplegia were able to ambulate efficiently using the powered exoskeleton for overground ambulation, providing the potential for functional gain and improved fitness.
\end{abstract}

Clinical Trial Registration: ClinicalTrials.gov; NCT01454570; "The ReWalk Exoskeletal Walking System for Persons with Paraplegia (VA_ReWalk)"; $\quad$ https://clinicaltrials.gov/ct2/show/ NCT01454570

Key words: 6MWT, ambulatory device, energy expenditure, metabolic, overground walking, oxygen uptake, paraplegia, powered exoskeleton, reciprocating gait orthosis, RGO, spinal cord injury.

\section{INTRODUCTION}

The wheelchair remains the primary option for mobility for persons with spinal cord injury (SCI) and lower-limb paralysis. However, at present, a few classes of assistive devices are commercially available to enable these people to ambulate overground. One option is hipknee-ankle-foot orthoses, which refer to a class of purely passive mechanical devices that enable the user to ambulate overground by keeping the knee in full extension but permitting rotation at the hip. This type of orthotic device is available in various versions and styles, which include hip guidance orthoses [1-3], reciprocating gait orthoses

\footnotetext{
Abbreviations: \%HRR = percentage of heart rate reserve, $\% \mathrm{VO}_{2} \mathrm{R}=$ percentage of oxygen uptake reserve, $6 \mathrm{MWT}=$ 6 min walk test, AIS = American Spinal Cord Injury Association Impairment Scale, ARGO = advanced reciprocating gait orthosis, $\mathrm{BMD}=$ bone mineral density, $\mathrm{bpm}=$ beats per minute, DXA = dual energy X-ray absorptiometry, EKG = electrocardiogram, FES = functional electrical stimulation, $\mathrm{HR}=$ heart rate, $\mathrm{RGO}=$ reciprocating gait orthosis, $\mathrm{RPE}=$ rate of perceived exertion, SCI = spinal cord injury, VA = Department of Veterans Affairs, $\mathrm{VO}_{2}=$ oxygen uptake.

*Address all correspondence to Ann M. Spungen, EdD; 130 W. Kingsbridge Rd, Rm 7A-13, Bronx, NY 10468; 718-5849000, ext 5814. Email: Ann.spungen@va.gov

http://dx.doi.org/10.1682/JRRD.2014.02.0060
} 
(RGOs) [1,4-5], and advanced reciprocating gait orthoses (ARGOs) [1,6]. Although these orthotics have been available to assist in ambulation for decades, they have not been adapted for routine use because of the high energy cost required to ambulate, difficulty in standing and sitting, and the inability to climb stairs $[1,6]$.

Other types of devices using functional electrical stimulation (FES) to ambulate overground have been investigated. These devices provide FES on specific muscle groups of the lower-limb muscles to power leg movement. Devices using FES alone have been successful in enabling users to ambulate, but their use has been limited because of rapid muscle fatigue and difficulty controlling joint movement [7]. Hybrid systems have also been explored, combining FES and a lower-limb orthotic [810] with decreased associated energy expenditure because of a reduction in muscle activity of the upper limb [11]. Further attempts to improve these systems have led to other variations, such as stored-energy hybrid systems, which combine FES with an orthotic brace that transfers energy from one joint movement to drive another joint [12-13], or controlled brake orthoses, which incorporate a computer-controlled brake system to lock out the joint and control joint speeds during ambulation [14]. Most of these devices remain as concepts or prototypes and have not been commercialized.

Dating back to the 1970s, efforts have been reported to make more efficient devices for overground ambulation by creating a robotic-based orthotic that incorporates motorized joints to power exoskeleton frames [15-16]. During this earlier era, the computing and battery technology was too primitive for this technology to progress to clinical use, and as such, further development of this approach was abandoned. However, recent technological advances have led to the aggressive development of a new series of powered exoskeletal devices that enable gait in persons with paralysis [17-23]. These exoskeletal systems also have the ability to address some of the limitations of prior orthotic devices because they are powered and can provide coordinated and controlled joint movements rather than rigid knee and ankle fixation. One system, ReWalk (ReWalk Robotics; Marlborough, Massachusetts), has been reported to be safe and well tolerated by the users [19-20,24] and approved by the U.S. Food and Drug Administration for use at home and in the community. The ReWalk powered exoskeleton allows the user with paralysis to perform maneuvers of standing, sitting, walking, and ascending and descending stairs [25-
27]. This expanded functionality addresses a few of the limitations of the nonpowered orthotic devices. To date, the energy expenditure required to use a powered exoskeleton system for overground ambulation has not been reported. As such, the aim of this study was to investigate energy expenditure and heart rate (HR) during powered exoskeletal-assisted use during sitting, standing, and walking. Oxygen uptake $\left(\mathrm{VO}_{2}\right)$ while using the powered exoskeleton was compared with that of other reports that have investigated the use of passive gait orthotics in persons with paraplegia.

\section{METHODS}

\section{Study Design}

A prospective, single-group observational study was conducted at the James J. Peters Department of Veterans Affairs (VA) Medical Center, Bronx, New York, after approval from the Institutional Review Board and registration with clinicaltrials.gov (NCT01454570). The primary aim was to measure $\mathrm{VO}_{2}$ and $\mathrm{HR}$ during powered exoskeletal-assisted walking during consecutive $6 \mathrm{~min}$ periods of sitting, standing, and walking.

\section{Participants}

To be eligible, each participant was required to have paraplegia for greater than 6 mo, be nonambulatory, be between 18 and $65 \mathrm{yr}$ old, and have a height between 152 and $193 \mathrm{~cm}$ and a weight less than $100 \mathrm{~kg}$. Participants were excluded from the study if they had any of the following: diagnosis of neurological impairment other than SCI, recent lower-limb fracture or proximal femur bone mineral density (BMD) $t$-score less than -3.5 and/or a BMD at the distal femur and/or proximal tibia less than $0.60 \mathrm{~g} / \mathrm{cm}^{2}$, pressure ulcers of the trunk and lower limb, contractures at the hip and knee greater than $20^{\circ}$, heterotopic ossification in the joints of the lower limbs, and females with pregnancy or who were trying to become pregnant during the study. A physical examination by the study physiatrist and determination of BMD by dual energy X-ray absorptiometry (DXA) were performed as part of the medical screening process. Each potential participant's level of impairment was evaluated by a trained physiatrist according to the American Spinal Cord Injury Association Impairment Scale (AIS). The DXA scan (Lunar iDXA, EnCORE software version 13.31.016, GE Medical Systems; Madison, Wisconsin) was performed 
to obtain regional measurements of BMD at the proximal femur, distal femur, and proximal tibia. The proximal femur was scanned according to the manufacturer specifications and the distal and proximal tibia regions were scanned according to the methods described by Shields et al. [28]. The study was discussed with the participants, and they were provided ample opportunity to ask questions. Once potential participants felt comfortable enrolling in the study, they signed an informed consent document prior to performing any procedures.

\section{Powered Lower-Limb Exoskeleton Description and Training}

The ReWalk powered exoskeleton was used in this clinical trial. All subjects were individually fitted to the exoskeleton according to pelvic width, thigh length, and shank length. The thigh length was determined by measuring from the most prominent point of the greater trochanter to the joint line of the knee. The shank length was determined by measuring the knee joint line center to the bottom of the foot. The pelvic band size was determined according to the width of the user's waist. Most participants wore their own shoes with the device, but some wore orthopedic shoes (Aetrex Worldwide Inc; Teaneck, New Jersey). Once the participant was fitted properly in the device, he or she participated in three training sessions per week. The first session included setup; additional adjustments to obtain proper fitting; and learning the maneuvers of standing up, sitting down, standing balance, and weight shifting as prerequisites to walking in the device. Each participant practiced these maneuvers until self-reported understanding of the maneuver and the trainers assessed that performance of the maneuvers could be accomplished with minimal to no assistance. For all participants in this study, the prerequisite skills were learned within the first session, and by the second session, all participants began to take steps with the exoskeleton.

Walking with the ReWalk powered exoskeleton is accomplished by a combination of using the mode selector to indicate the desire to walk followed by body movement, measured by a tilt sensor affixed to the vertical thoracic upright posts of the device that are immediately superior to the hip joint $[25,27]$. The mode selector is a controller worn on the wrist that is used to indicate that a specific maneuver is desired. In order to rise from the seated position to standing (sit-to-stand), the appropriate mode is selected, followed by a $5 \mathrm{~s}$ pause that permits time for proper crutch placement and to allow for the user to shift his or her center of mass forward, above his or her feet. The motors then raise the individual upright into the standing position. During the sit-to-stand maneuver, the system has a safety mechanism in place that monitors the exoskeleton for proper positioning. If the user is not in an appropriate position to stand, the safety mechanism will be triggered and the device will return to the sitting position. Going from standing to the sitting position (standto-sit), the appropriate mode is selected, followed by a $5 \mathrm{~s}$ pause to allow the user to shift his or her weight slightly backward to enable the person to maintain stability when being lowered during the movement to sit. Once standing, walking is accomplished with a combination of body position, dynamic trunk posture, weight shifting, and arm/crutch placement. To initiate walking, which can only be enabled while standing, the user chooses the walk icon on the mode selector, followed by a slight diagonal leftward and forward shift; the weight shift must be sufficient to move the tilt sensor (according to the settings predetermined for that participant), and to offload the right leg to allow it to swing forward. Once the right leg has completed the swing motion, the user shifts his or her body weight onto this leg, which will lead to the unweighting of the left leg and triggering the left leg to pass through the swing portion of the gait. The subsequent steps are initiated by the uninterrupted shifting onto the contralateral leg that has just completed the swing phase, resulting in continuous ambulation, similar to natural walking [29]. The device can be triggered to stop walking and return to the standing mode if no forward tilt is sensed for at least $2 \mathrm{~s}$. The other method for stopping, which all participants choose to use the majority of the time, was performed by not fully weight shifting laterally so that their body position failed to allow the swing leg to clear the floor, resulting in activation of a safety mechanism that senses sufficient resistance to movement to cause the device to discontinue walking.

A trainer was continuously present to provide handson assistance for balance during the initial sessions, as needed. The amount of assistance provided was determined as moderate, minimal, and no assistance and defined as follows: moderate assistance was when the trainer provided a substantial effort and verbal cues to maintain proper body positioning to enable the person to ambulate with the powered exoskeleton, minimal assistance was when the trainer provided a small effort and verbal cues to enable the participant to ambulate, and no 
assistance was when the participant could ambulate with no trainer assistance. In the no assistance sessions, the trainer was close in order to spot the participant for safety but did not have any hand contact on the participant to aid in the ambulation. The participant's body weight was never offloaded by the trainer or by an overhead harness at any of the levels of assistance.

All participants were provided with an in-depth explanation and visual examples of how to use the powered exoskeleton to ambulate. Initially, levels of assistance provided varied, but as the proficiency of each participant with the device improved, the level of assistance by the trainer was reciprocally reduced. During the initial sessions, tolerance to walking was variable, but by the beginning of the third week of training, all participants were able to remain in the device for training sessions that lasted between 60 and $90 \mathrm{~min}$. These training sessions included donning and doffing the device and at least two 15 min bouts of walking training during each session. Participants were allowed periods of rest as needed by either standing with the device while leaning on a wall or by sitting while wearing the device. At a randomly selected time point during the session, determined by the trainer, walking performance was measured by a 6 min walk test (6MWT) for distance, with the walking speed readily calculated (distance walked [in meters]/ $360 \mathrm{~s}=\mathrm{m} / \mathrm{s}$ ). In addition, at the end of the each training session the participant reported the rate of perceived exertion (RPE) based on the Borg scale (exertion rated from 6 to 20) [30].

\section{Metabolic Testing Protocol}

$\mathrm{VO}_{2}$ and $\mathrm{HR}$ measurements were obtained when the participants could ambulate using the powered exoskeleton continuously, even if they needed some level of assistance, in proximity to the 40th training session. Participants wore a face mask attached to a portable metabolic acquisition system (Oxycon Mobile; Jaeger, Germany) and 12-lead electrocardiogram (EKG). $\mathrm{VO}_{2}$ normalized to body weight (milliliter per kilogram per minute) and HR values were obtained from the metabolic cart, which supplied averages of every 1 min period of recording. The testing session was composed of three consecutive testing conditions: seated rest (SIT), exoskeleton-assisted standing (STAND), and exoskeletonassisted walking (WALK). Each testing condition was $6 \mathrm{~min}$ in duration and started immediately after completing the transition to the next testing condition. HR and
$\mathrm{VO}_{2}$ values for each condition were calculated by averaging the six 1 min periods. The distance traveled over the 6 min WALK condition was used to calculate an overall walking speed during the metabolic test. Comparisons between the participant's previous 6MWT performance without versus with the face mask and the other metabolic equipment were noted.

The $\mathrm{VO}_{2}$ and $\mathrm{HR}$ during WALK were reported relative to exercise intensity and expressed as a percentage of oxygen uptake reserve $\left(\% \mathrm{VO}_{2} \mathrm{R}\right)$ and percentage of $\mathrm{HR}$ reserve (\%HRR). These variables of efficiency were calculated based on a modification of the Karvonen method [31] using the Equations 1 and 2:

$$
\begin{aligned}
\% V O_{2} R & =\frac{V O_{2 W A L K}-V O_{2 S I T}}{V O_{2 p M a x}-V O_{2 S I T}} \times 100 \text { and } \\
\% H R R & =\frac{H R_{W A L K}-H R_{\text {SIT }}}{H R_{\text {pMax }}-H R_{\text {SIT }}} \times 100 .
\end{aligned}
$$

$\mathrm{VO}_{2}$ and $\mathrm{HR}$ were measured during the SIT $\left(\mathrm{VO}_{2 \mathrm{SIT}}\right.$, $\left.\mathrm{HR}_{\text {SIT }}\right)$ and WALK $\left(\mathrm{VO}_{2 \text { WALK }}, \mathrm{HR}_{\text {WALK }}\right)$ conditions. Because of paralysis, the participants were not able to perform lower-limb maximal $\mathrm{VO}_{2}$ testing; as such, predicted maximal $\mathrm{VO}_{2}\left(\mathrm{VO}_{2 \mathrm{pMax}}\right)$ was estimated in two different ways. In order to relate the $\mathrm{VO}_{2 \mathrm{pMax}}$ to values observed with lower-limb exercise $\left(\mathrm{VO}_{2 \mathrm{pMax}} \mathrm{LEGS}\right)$, the values were obtained from the table by Heyward [32] for sex, age, and the assumption of a "fair" cardiorespiratory level of fitness. The $\mathrm{VO}_{2 \mathrm{pMax}} \mathrm{LEGS}$ chosen was the lowest within the "fair" range in order to use a conservative representation of a sedentary population. The second value used was based on a review by Noreau and Shephard, who presented maximal $\mathrm{VO}_{2}$ based on upper-arm crank ( $\mathrm{VO}_{2 \mathrm{pMax}} \mathrm{ARMS}$ ) exercise from 12 reports in persons with chronic SCI [33]. The median value of $25.3 \mathrm{~mL} / \mathrm{kg} / \mathrm{min}$ reported was chosen. The predicted maximal HR was determined by the standard equation $\mathrm{HR}_{\mathrm{pMax}}=220$ - age [34].

\section{Statistics}

Statistical analyses were performed using JMP version 8.0.1 (SAS Institute; Carey, North Carolina), and the level of significance was set at $p<0.05$. Descriptive statistics are reported as mean \pm standard deviation for all continuous outcome variables. $\mathrm{HR}$ and $\mathrm{VO}_{2}$ were tested for significance using a within-subject repeated measures 
analysis of variance for condition (SIT, STAND, and WALK). Post hoc analyses were performed using TukeyKramer pairwise tests for each outcome variable that demonstrated a significant main effect. Differences in walking speed during the metabolic test (walking wearing the metabolic mask) and walking speed from the training session immediately prior to the metabolic test (walking without the metabolic mask) were determined using a paired $t$-test. In order to determine the influence of level of injury, lower-limb motor score, level of assistance, and walking speed on $\mathrm{HR}$ and $\mathrm{VO}_{2}$ during the WALK condition, two separate stepwise regression models were used. Level of assistance was categorized to either no assistance (value of 1 ) or assistance (value of -1 ). Additional comparisons were made on $\mathrm{VO}_{2}, \mathrm{HR}$, and RPE during the WALK condition for participants who needed assistance compared with those who used the powered exoskeleton without any assistance by unpaired $t$-test. Bonferoni correction was applied to multiple pairwise comparisons to ensure appropriate significance was obtained.

\section{RESULTS}

Eleven persons with SCI were screened for eligibility. Two participants did not meet the BMD requirements during the screening process and one withdrew after $1 \mathrm{wk}$ of training because of scheduling conflicts, leaving a total of eight participants who remained in the study and were included for data analysis.

The neurological levels of SCI for all eight participants were classified as AIS A if they had lack of sacral sparing in the S4-S5 sacral segments or B if they had sacral sparing and no motor function below the level of lesion. Three participants had zones of partial preservation that included some lower-limb motor function but were classified as AIS A because of the lack of sacral sparing (Table 1). Participants with a zone of partial preservation were not encouraged nor asked to refrain from using their residual function; these participants may be assumed to have utilized their residual function, although this assumption would be purely speculative. All subjects had full upper-limb function with the exception of one subject, who scored 4 of 5 on the upper limbs for both the right and left side. The average age of the participants was $46 \pm 12 \mathrm{yr}$, and the additional relevant demographic data are presented in Table 1. At the time of testing, four participants were able to use the exoskeletal
Table 1.

Demographic characteristics of the study participants.

\begin{tabular}{llcccccc}
\hline & Sex & $\begin{array}{c}\text { Age } \\
(\mathbf{y r})\end{array}$ & $\begin{array}{c}\text { AIS } \\
\text { Grade }\end{array}$ & $\begin{array}{c}\text { AIS } \\
\text { Level }\end{array}$ & $\begin{array}{c}\text { DOI } \\
(\mathbf{y r})\end{array}$ & $\begin{array}{c}\text { Weight } \\
\mathbf{( k g )}\end{array}$ & LEMS \\
\hline $1^{*}$ & $\mathrm{M}$ & 44 & $\mathrm{~A}$ & $\mathrm{~T} 4$ & 4.5 & 77 & 4 \\
$2^{\dagger}$ & $\mathrm{F}$ & 58 & $\mathrm{~A}$ & $\mathrm{~T}^{\dagger}$ & 1.5 & 64 & 0 \\
$3^{*}$ & $\mathrm{M}$ & 61 & $\mathrm{~A}$ & $\mathrm{~T} 11$ & 14 & 73 & 3 \\
4 & $\mathrm{M}$ & 24 & $\mathrm{~A}$ & $\mathrm{~T} 5$ & 5 & 75 & 0 \\
5 & $\mathrm{M}$ & 40 & $\mathrm{~B}$ & $\mathrm{~T} 1$ & 1.5 & 88 & 0 \\
6 & $\mathrm{M}$ & 56 & $\mathrm{~A}$ & $\mathrm{~T} 9$ & 3 & 84 & 0 \\
$7^{*}$ & $\mathrm{M}$ & 50 & $\mathrm{~A}$ & $\mathrm{~T} 7$ & 12 & 96 & 30 \\
8 & $\mathrm{M}$ & 37 & $\mathrm{~A}$ & $\mathrm{~T} 2$ & 6 & 66 & 0 \\
\hline
\end{tabular}

*Although subjects had complete spinal cord injury, these subjects also had zone of partial motor preservation that included some volitional movement of lower limbs.

${ }^{\dagger}$ Subject 2 had incomplete motor and sensory paralysis at C5 (cervical 5). However, upper-limb motor score on partially paralyzed muscles was scored 4 out of 5 (AIS scale). Sensation was present for this subject to T8, with loss of sensation and motor function below T8.

AIS $=$ American Spinal Cord Injury Association Impairment Scale, DOI $=$ duration of injury, $\mathrm{F}=$ female, LEMS = lower-limb motor score, $\mathrm{M}=$ male, $\mathrm{T}$ = thoracic.

device independently with no assistance, three needed minimal assistance consisting of light assistance and supervision, and one needed moderate assistance to ambulate. None of the participants ambulated with any type of overhead system to offload body weight. If assistance was provided by the trainer, it was by assisting with lateral displacement of the pelvis to aid the participant in maintaining balance and proper load over the stance leg.

The values measured during one session for $\mathrm{VO}_{2}$ during SIT, STAND, and WALK conditions and the calculated WALK $\% \mathrm{VO}_{2} \mathrm{R}$ are reported for each participant (Table 2). The mean $\mathrm{VO}_{2}$ for SIT and STAND were $3.5 \pm$ $0.4 \mathrm{~mL} / \mathrm{kg} / \mathrm{min}$ (range $=2.8-4.2$ ) and $4.3 \pm 0.9 \mathrm{~mL} / \mathrm{kg} /$ min (range $=3.4-6.2$ ), respectively, and were not significantly different. However, as expected, the $\mathrm{VO}_{2}$ response during WALK was significantly greater than both SIT and STAND (11.2 \pm 1.7 vs $3.5 \pm 0.4$ and $4.3 \pm 0.9 \mathrm{~mL} / \mathrm{kg} /$ min, respectively; $F=61.13, p<0.001$ ) (Figure 1). The increase in $\mathrm{VO}_{2}$ from walking in the exoskeleton represented a $\% \mathrm{VO}_{2} \mathrm{R}$ Legs of $24 \pm 4$ percent or $\% \mathrm{VO}_{2} \mathrm{R}$ Arms of $35 \pm 7$ percent; thus, during WALK, participants attained approximately one-quarter to one-third of their estimated maximum $\mathrm{VO}_{2}$ reserve. No significant variables were found from the stepwise regression model for $\mathrm{VO}_{2}$.

The measured and calculated values for $\mathrm{HR}$ and \%HRR during SIT, STAND, and WALK are reported by participant (Table 2) and displayed in box plot format (Figure 2). A nonsignificant increase was observed in 
Table 2.

Oxygen uptake $\left(\mathrm{VO}_{2}\right)$ and heart rate (HR) obtained while sitting, standing, and walking.

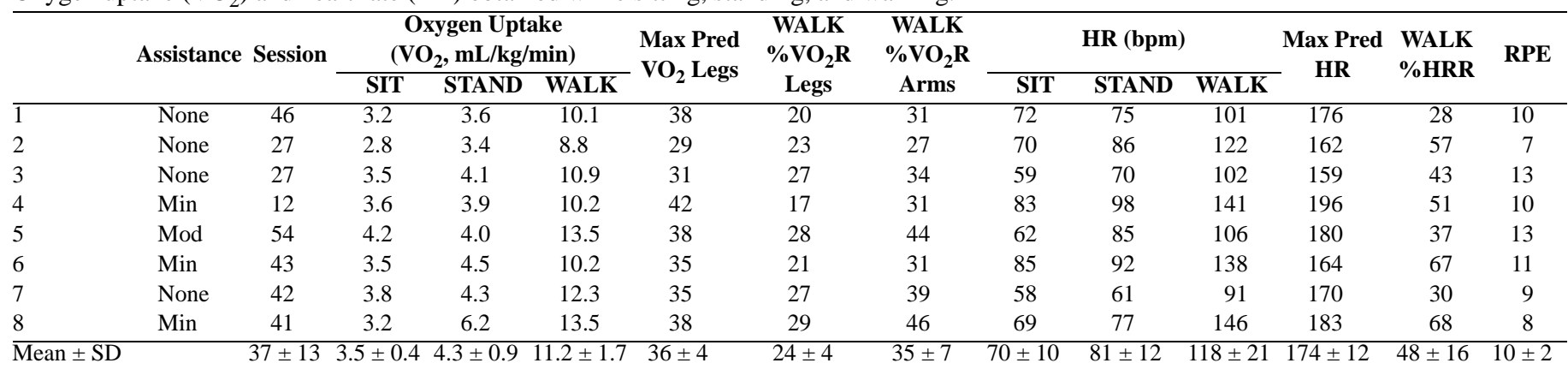

Assistance $=$ level of assistance given to participant during that testing day where None is no assistance at all, Min is minimal contact with person, and Mod is moderate amount of assistance to help person maintain proper positioning during walking trial; bpm = beats per minute; HR = heart rate; Max Pred HR = maximum predicted HR (220 - age); Max Pred $\mathrm{VO}_{2}$ Legs = maximum predicted $\mathrm{VO}_{2}$ based on table by Heyward [32] during lower-limb exercise; RPE = rate of perceived exertion developed by Borg [30]; SD = standard deviation; Session = session number in which metabolic measurement was obtained; SIT = sitting at rest condition; $\mathrm{STAND}$ = standing condition; WALK = walking condition; Walk \%HRR = percentage of heart rate reserve while walking; $\mathrm{WALK}_{\mathrm{V}} \mathrm{VO} \mathrm{O}_{2} \mathrm{R}$ Arms $=$ percentage of oxygen uptake reserve while walking using value of 25.25 as maximal $\mathrm{VO}_{2}$ by arm crank based on reported values by Noreau and Shephard [33]; WALK \% $\mathrm{VO}_{2} \mathrm{R}$ Legs = percentage of oxygen uptake reserve while walking based on table by Heyward [32].

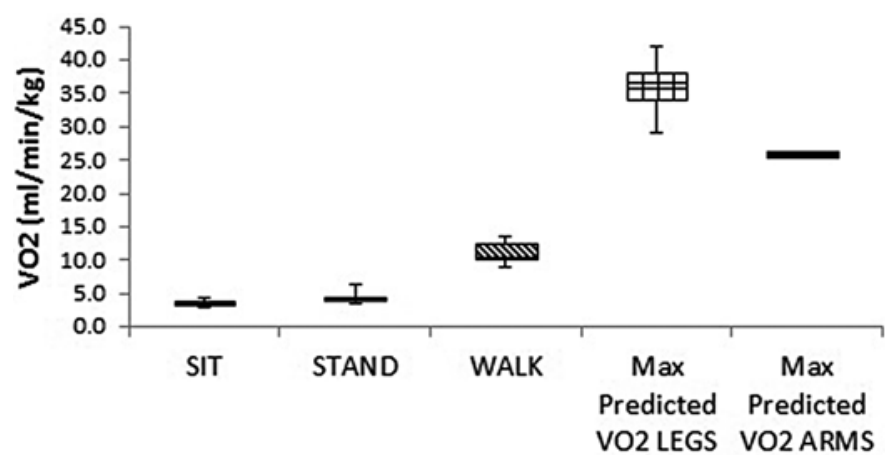

Figure 1.

Box plot of oxygen uptake $\left(\mathrm{VO}_{2}\right)$ is displayed for each condition (SIT, STAND, and WALK) and estimated maximal (Max) predicted $\mathrm{VO}_{2}$ using prediction based on leg and arm crank exercises. Significant differences $(p<0.001)$ between WALK compared with SIT and STAND.

HR from SIT to STAND. The HR response during WALK was significantly increased above that of both SIT and STAND (118 \pm 21 vs $70 \pm 10$ and $81 \pm 12$ beats per minute [bpm], respectively, $F=51.87, p<0.001$ ), which represented a \%HRR of $48 \pm 16$ percent. Thus, during WALK, participants attained approximately one half of their estimated maximum HR reserve, which would indicate a moderate level of activity. The stepwise regression model for HR resulted in only level of assistance being inversely related to HR during the WALK condition $(p=0.04)$.

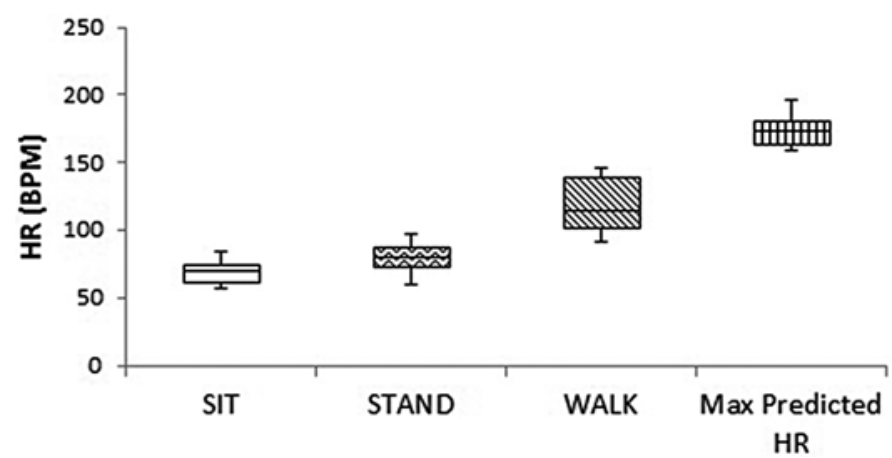

Figure 2.

Box plot of heart rate (HR) is displayed for each condition (SIT, STAND, and WALK) and estimated maximal (Max) predicted HR. Significant differences $(p<0.001)$ between WALK compared with SIT and STAND. BPM = beats per minute.

An unpaired $t$-test also revealed that participants who received assistance while walking had higher average HR values than those who received no assistance (133 \pm 8 vs $104 \pm 8 \mathrm{bpm}, p=0.047$ ); however, this comparison was no longer statistically significant once a Bonferoni correction was applied. The mean values for $\mathrm{VO}_{2}$ were slightly higher for those who needed assistance than those who did not $(11.9 \pm 0.8$ vs $10.5 \pm 0.8 \mathrm{~mL} / \mathrm{kg} / \mathrm{min})$, but the difference was not significant.

The RPEs reported by each participant at the end of the testing day for the walking performed are presented in Table 2. On average, the participants reported RPEs 
ranging from very, very light (7) to somewhat hard (13), with an average RPE of very light to fairly light (10 \pm 2$)$.

Average walking velocities while wearing the metabolic testing equipment (face mask, EKG leads and vest) were significantly slower than those attained during previous training sessions when metabolic testing was not being performed $(0.22 \pm 0.11$ vs $0.27 \pm 0.11 \mathrm{~m} / \mathrm{s}, p<$ 0.001) (Table 3).

\section{DISCUSSION}

Use of an exoskeletal system that requires increased energy expenditure without requiring excessive effort is desirable. The $\mathrm{HR}$ and $\mathrm{VO}_{2}$ responses to exoskeletalassisted walking in persons with motor-complete paraplegia were demonstrated to be mildly increased from sitting and standing but well below maximal predicted value for both variables. The seated rest $\mathrm{VO}_{2}(3.5 \pm 0.4 \mathrm{~mL} / \mathrm{kg} /$ min) observed in this investigation was a value comparable with those for nondisabled persons and for those with SCI at rest [6,32,34-35]. The standing condition resulted in a nonsignificant increase in $\mathrm{VO}_{2}(4.3 \pm 0.9 \mathrm{~mL} / \mathrm{kg} /$ min), which was within a similar range to those of previously reported values for nondisabled individuals and individuals with SCI when standing [6,36]. Our findings indicate that participants performed exoskeletal-assisted walking at about half of their estimated maximal HR reserve, which represents a moderate level of intensity

Table 3.

Overground speed for participants using ReWalk Exoskeleton and predicted speed for nondisabled individuals.

\begin{tabular}{lcc}
\hline & $\begin{array}{c}\text { Speed with } \\
\text { Metabolic Mask } \\
(\mathbf{m} / \mathbf{s})\end{array}$ & $\begin{array}{c}\text { Speed Without } \\
\text { Metabolic Mask } \\
\mathbf{( m / s )}\end{array}$ \\
\hline 1 & 0.34 & 0.38 \\
2 & 0.30 & 0.34 \\
3 & 0.12 & 0.14 \\
4 & 0.08 & 0.17 \\
5 & 0.08 & 0.15 \\
6 & 0.24 & 0.30 \\
7 & 0.36 & 0.42 \\
8 & 0.25 & 0.28 \\
\hline Mean \pm SD & $0.22 \pm 0.11$ & $0.27 \pm 0.11$ \\
\hline \multicolumn{2}{l}{ Note: Speed with metabolic mask was calculated during 6 min of walking dur- } \\
ing metabolic test. Speed without metabolic mask was calculated from 6 min \\
walk test obtained during session prior to metabolic test. \\
SD = standard deviation. \\
\hline \hline
\end{tabular}

[34]. Using either the leg or arm estimates for $\mathrm{VO}_{2}$ as an indicator of level of effort, an even lower percent of maximal effort was found while performing exoskeletalassisted walking, with a $\% \mathrm{VO}_{2} \mathrm{R}$ Legs of 24 percent and $\% \mathrm{VO}_{2} \mathrm{R}$ Arms of 35 percent observed. The mild $\mathrm{VO}_{2}$ percent efforts were supported by the participant's average RPE value of 10, representing a very light to fairly light effort. The relatively modest energy demands of walking using a powered exoskeleton approach what the American College of Sports Medicine has recommended as "minimal training intensity threshold for improvement in $\mathrm{VO}_{2 \text { max }}$, and the lactate threshold is approximately 40$50 \%$ of $\mathrm{VO}_{2} \mathrm{R}$ or HRR" [37]. Thus, walking in this powered exoskeleton has the possibility to be used routinely. With an increase in regular activity, the possibility to improve the adverse health-related consequences of paralysis, such as adiposity, insulin resistance, carbohydrate tolerance, lipid profile, and psychological wellbeing may also exist [38-44].

The increased $\mathrm{VO}_{2}$ for walking, above that of sitting and standing, is evidence that additional effort from the user is required to perform ambulation in the exoskeleton (i.e., the exoskeleton is not performing all of the work for ambulation). Previous investigations measuring pressure under the foot when ambulating in the exoskeleton demonstrated that the less skilled participants were not loaded to the same degree as those who were more proficient [29]. Although measurements of pressures on the crutches were not observed, it was hypothesized that the less skilled participants offloaded some weight onto their crutches. In addition, although anecdotal, trainers have asked the participants with less skill to minimize pressure on their hands, but participants indicate that the load on their arms makes them feel more secure because they are unable to feel the floor with their legs. Another explanation for the increased $\mathrm{VO}_{2}$ during WALK may have been the increased use of trunk and shoulder muscles required for weight shifting and balancing. Propelling the body forward with hip extension was performed by the exoskeleton; however, the participants purposefully use their upper bodies to shift laterally while subsequently maintaining balance on the stance limb while the contralateral leg swings during ambulation. This action required additional effort than that expended during static standing balance.

An explanation for the increased HR in those who required assistance compared with those who walked with no assistance may be due to the increased use of 
their arms and weight on the crutches. Our finding is based on a small number of participants in each group but suggests that those with less skill using the device may expend more effort, which may be due to increased use of their arms in order to ambulate than those who walk more independently. Perhaps with a larger sample size this difference will attain significance. In the group requiring assistance, continued practice may result in a reduction of $\mathrm{VO}_{2}$ and $\mathrm{HR}$ while ambulating.

Measurements of $\mathrm{VO}_{2}$ during ambulation using passive orthotic devices, such as RGO, ARGO, Parawalker, and Craig-Scott braces, are presented in Table 4. While walking at similar velocities, the $\mathrm{VO}_{2}$ values observed during the exoskeletal-assisted walking were within the lower range of these prior studies that employed passive devices. In a report by Kawashima et al., who performed a similar study, $\mathrm{VO}_{2}$ and HR were obtained in 10 participants with paraplegia who used an RGO while sitting and standing at rest, after which 20 min of walking was performed [5]. The $\mathrm{VO}_{2}$ during the standing condition observed by Kawashima et al. was much higher than that observed in the current study $(6.2 \pm 1.8$ vs $4.3 \pm 0.9 \mathrm{~mL} /$ $\mathrm{kg} / \mathrm{min}$, respectively); however, the HR was similar (86 \pm 24.78 vs $81 \pm 12 \mathrm{bpm}$, respectively). The difference in $\mathrm{VO}_{2}$ during standing may have been attributed to increased effort from the trunk and upper limbs to maintain standing balance [5] because of a less rigid hip joint in the RGO. The subsequent walking $\mathrm{VO}_{2}$ and $\mathrm{HR}$ values were higher in the participants reported using this particular RGO than those in the present study using the powered exoskeleton $\left(\mathrm{VO}_{2}: 18.2 \pm 3.8\right.$ vs $11.2 \pm 1.7 \mathrm{~mL} / \mathrm{kg} /$ min, HR: $133 \pm 21$ vs $118 \pm 21 \mathrm{bpm})$, indicating greater efficiency for walking while using the powered exoskeleton. The increased $\mathrm{VO}_{2}$ and $\mathrm{HR}$ while using the RGO may have been due to the requirement of the user to balance on one limb while simultaneously using the upper body to provide a torque to extend the hip joint of the stance leg and flexing the contralateral hip joint to swing that leg forward. The RGO has a locked knee joint, which may necessitate more lateral movement as well as the desire to offload the body onto the crutches in order to offload the leg. Lastly, walking speed or the duration of the walking measurement could have led to the differences observed between the two devices. There were a few differences in the demographics of the study participants, but the main difference between the two studies was that Kawashima et al. reported that persons using the RGO walked at a faster speed during the metabolic test than those in the current study $(0.33 \pm 0.10$ vs $0.22 \pm$ $0.11 \mathrm{~m} / \mathrm{s}$ ). However, when users in the two studies were compared while walking without the metabolic mask, the powered exoskeletal-assisted walking participants were closer to the average walking speed of the Kawashima study group $(0.27 \pm 0.11$ vs $0.35 \pm 0.10 \mathrm{~m} / \mathrm{s})$. The $\mathrm{VO}_{2}$ and gait velocities from other reports (Table 4) showed that the $\mathrm{VO}_{2}$, although not always lower using the powered exoskeleton versus the other nonpowered devices, was generally at the lower range when walking at similar gait velocities.

Overground walking speeds during training were significantly faster than those obtained while performing the metabolic test (Table 3). When conducting the metabolic test, the face mask partially obstructed the participant's

Table 4.

Energy consumption and gait speed for each study.

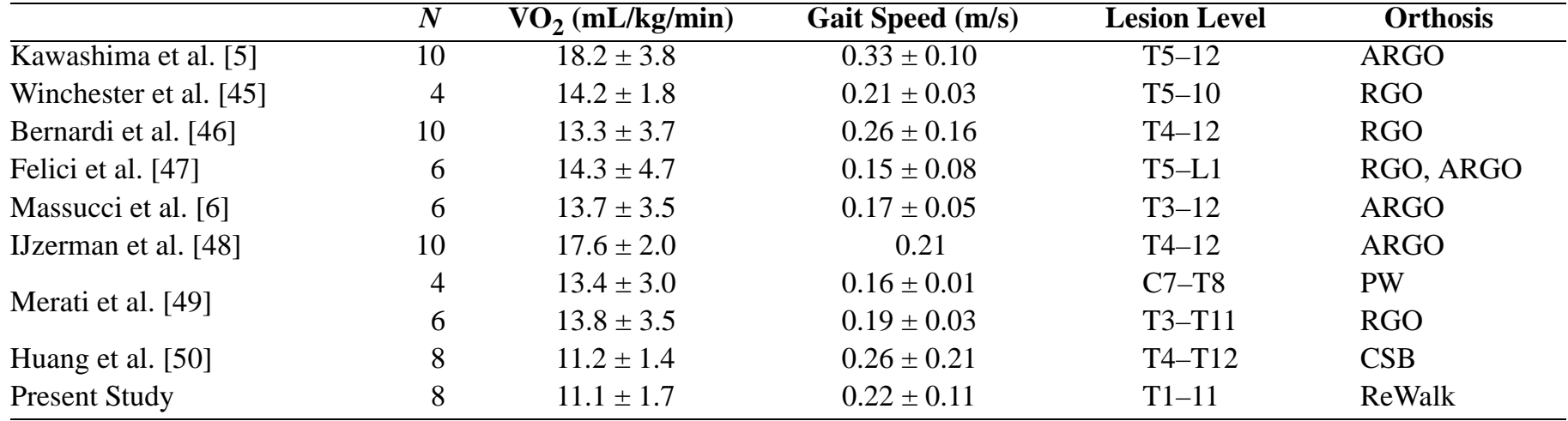

Note: $\mathrm{VO}_{2}$ and speed are presented as mean \pm standard deviation.

$\mathrm{ARGO}=$ advanced reciprocating gait orthosis, $\mathrm{C}=$ cervical, $\mathrm{CSB}=$ Craig-Scott brace, $\mathrm{PW}=$ Parawalker, $\mathrm{RGO}=$ reciprocating gait orthosis, $\mathrm{T}=$ thoracic, $\mathrm{VO} \mathrm{O}_{2}=$ oxygen uptake. 
field of vision. One of the evident challenges in using an exoskeletal device for overground ambulation is that the person with SCI has decreased to absent sensation of the position of their lower limbs. As such, participants initially made an effort to visualize their legs while walking, but the $\mathrm{VO}_{2}$ mask partially obstructed direct visual feedback of the location of their legs, which resulted in slower average walking speeds. However, as the user attains a greater degree of skill using the device, the participants report cueing on the sound of the motors to infer the position of their legs in the absence of visual cues. This consideration may skew the calculation of energy cost when normalizing the energy expenditure to walking speed and thus generate spuriously higher values.

A limitation of this study was that the individual participant's maximal $\mathrm{VO}_{2}$ was not known due to the inability to perform a maximal lower-limb exercise test because of paraplegia. Maximal values of $\mathrm{VO}_{2}$ during upper-limb values have been reported to be approximately 70 percent lower than those performed with the lower limbs [51-53]. Therefore, predicted values from both lower and upper limbs were used in our model. A predicted maximal fitness level of "fair" at the lowest level to provide a conservative estimate was used based on maximal exercise with the lower limb using data from Heyward [32], which resulted in a $24 \% \mathrm{VO}_{2} \mathrm{R}$. The $\% \mathrm{VO}_{2} \mathrm{R}$ predicted based on an arm maximal test from values reported by Noreau and Shephard [33] resulted in a $\% \mathrm{VO}_{2} \mathrm{R}$ of 35 percent. This approach to predicted $\% \mathrm{VO}_{2} \mathrm{R}$ has inherent inaccuracies because it is an estimate of $\mathrm{VO}_{2 \max }$ but should provide insight to the relative degree of $\mathrm{VO}_{2}$ during ambulation. Greater confidence may be placed in the \%HRR, which was about one half the maximal predicted HR (220 bpm), because this is a universally accepted value and is not affected by levels of fitness [34].

Additional work to investigate energy expenditure while using robotic exoskeletons would clarify several issues. Longitudinal studies to determine whether a relationship exists between long-term use, the degree of energy expenditure, and the subsequent potential medical benefits would be of clinical relevance. With practice using powered exoskeletal devices, energy expenditure may be diminished with the acquisition of improved skill and efficiency, with the distinct possibility that during faster walking velocities the associated work will remain fairly constant. Electromyography profiles while ambulating in the powered exoskeleton systems may also be relevant to identify lower-limb muscle activation, which may be an important contributor to increases in energy expenditure in those with a partial zone of motor preservation [54]. It should be appreciated that advancements in the powered exoskeleton design may result in lower energy expenditure, which could then serve to reduce any salutatory metabolic and/or cardiovascular benefits to be gained from its use.

\section{CONCLUSIONS}

This report is the first to determine energy expenditure of powered exoskeletal-assisted walking by use of the ReWalk system in persons with SCI. While using the powered exoskeleton, persons with SCI were able to successfully ambulate overground with training and practice. As with other physical activities, some users attained more competence and independence in the device. Although the results of this study did not address longterm changes in oxygen demand with habitual use, routine use of the device to increase activity energy expenditure would be expected to have positive cardiopulmonary and metabolic benefits. The level of effort required to use the ReWalk exoskeleton system to ambulate appears to be acceptable, and, as such, could be envisioned to be a device that persons with SCI would use in their daily lives.

\section{ACKNOWLEDGMENTS}

\section{Author Contributions:}

Study concept and design: C. Cirnigliaro, W. A. Bauman, A. M. Spungen, P. Asselin.

Acquisition of data: P. Asselin, S. Knezevic.

Analysis and interpretation of data: P. Asselin, S. Knezevic,

C. Cirnigliaro, W. A. Bauman, A. M. Spungen.

Drafting of manuscript: P. Asselin.

Critical revision of manuscript for important intellectual content:

W. A. Bauman, A. M. Spungen.

Obtained funding: W. A. Bauman, A. M. Spungen.

Study supervision: S. Kornfeld, I. Agranova-Breyter.

Financial Disclosures: The authors have declared that no competing interests exist.

Funding/Support: This material was based on work supported by the VA Rehabilitation Research \& Development National Center of Excellence for the Medical Consequences of Spinal Cord Injury (VA RR\&D B9212C). Two of the four ReWalk devices were obtained on a loaner basis at no cost from Argo Medical Technologies (Marlborough, Massachusetts). Orthopedic shoes used in this trial were donated by Aetrex Worldwide Inc. (Teaneck, New Jersey). 
Additional Contributions: The efforts of Denis Doyle-Green and his involvement with the training program are greatly appreciated, and we are thankful for his assistance. In addition, this work could not have been accomplished without the support of the Rehabilitation and Spinal Cord Injury Services at the James J. Peters VA Medical Center. Institutional Review: This study was reviewed and approval was obtained by the Institutional Review Board at the James J. Peters VA Medical Center, Bronx, New York. The study was registered with ClinicalTrials.gov (NCT01454570). Informed consent was obtained from all study participants prior to performing any study-related procedure.

Participant Follow-Up: The authors do not plan to inform participants of the publication of this study.

\section{REFERENCES}

1. Nene AV, Hermens HJ, Zilvold G. Paraplegic locomotion: A review. Spinal Cord. 1996;34(9):507-24.

[PMID:8883185]

http://dx.doi.org/10.1038/sc.1996.94

2. Nene AV, Patrick JH. Energy cost of paraplegic locomotion using the ParaWalker-electrical stimulation "hybrid" orthosis. Arch Phys Med Rehabil. 1990;71(2):116-20. [PMID:2302043]

3. Nene AV, Patrick JH. Energy cost of paraplegic locomotion with the ORLAU ParaWalker. Paraplegia. 1989;27(1):5-18. [PMID:2922207] ttp://dx.doi.org/10.1038/sc.1989.2

4. Sykes L, Ross ER, Powell ES, Edwards J. Objective measurement of use of the reciprocating gait orthosis (RGO) and the electrically augmented RGO in adult patients with spinal cord lesions. Prosthet Orthot Int. 1996;20(3):182-90. [PMID:8985998]

5. Kawashima N, Taguchi D, Nakazawa K, Akai M. Effect of lesion level on the orthotic gait performance in individuals with complete paraplegia. Spinal Cord. 2006;44(8):487-94. [PMID:16550216] http://dx.doi.org/10.1038/sj.sc.3101916

6. Massucci M, Brunetti G, Piperno R, Betti L, Franceschini $\mathrm{M}$. Walking with the advanced reciprocating gait orthosis (ARGO) in thoracic paraplegic patients: Energy expenditure and cardiorespiratory performance. Spinal Cord. 1998; 36(4):223-27. [PMID:9589520]

http://dx.doi.org/10.1038/sj.sc.3100564

7. Graupe D, Suliga P, Prudian C, Kohn KH. Stochasticallymodulated stimulation to slow down muscle fatigue at stimulated sites in paraplegics using functional electrical stimulation for leg extension. Neurol Res. 2000;22(7):703-4. [PMID:11091976]

8. Solomonow M, Baratta R, Hirokawa S, Rightor N, Walker W, Beaudette P, Shoji H, D’Ambrosia R. The RGO Generation II: Muscle stimulation powered orthosis as a practical walking system for thoracic paraplegics. Orthopedics. 1989;12(10):1309-15. [PMID:2798239]

9. Hirokawa S, Solomonow M, Baratta R, D’Ambrosia R. Energy expenditure and fatiguability in paraplegic ambulation using reciprocating gait orthosis and electric stimulation. Disabil Rehabil. 1996;18(3):115-22.

[PMID:8695882]

http://dx.doi.org/10.3109/09638289609166028

10. McClelland M, Andrews BJ, Patrick JH, Freeman PA, el Masri WS. Augmentation of the Oswestry Parawalker orthosis by means of surface electrical stimulation: Gait analysis of three patients. Paraplegia. 1987;25(1):32-38. [PMID:3562054] http://dx.doi.org/10.1038/sc.1987.10

11. Petrofsky JS, Smith JB. Physiologic costs of computercontrolled walking in persons with paraplegia using a reciprocating-gait orthosis. Arch Phys Med Rehabil. 1991; 72(11):890-96. [PMID:1929807] http://dx.doi.org/10.1016/0003-9993(91)90007-6

12. Durfee WK, Rivard A. Preliminary design and simulation of a pneumatic, stored-energy, hybrid orthosis for gait restoration. Proceedings of the ASME 2004 International Mechanical Engineering Congress and Exposition; 2004 Nov 13-19; Anaheim, CA.

13. Durfee WK, Rivard A. Design and simulation of a pneumatic, stored-energy, hybrid orthosis for gait restoration. J Biomech Eng. 2005;127(6):1014-19. [PMID:16438242] http://dx.doi.org/10.1115/1.2050652

14. Goldfarb M, Korkowski K, Harrold B, Durfee W. Preliminary evaluation of a controlled-brake orthosis for FESaided gait. IEEE Transactions on Neural Systems and Rehabilitation Engineering. 2003;11(3):241-48.

15. Hughes J. Powered lower limb orthotics in paraplegia. Paraplegia. 1972;9(4):191-93. [PMID:5010144] http://dx.doi.org/10.1038/sc.1971.31

16. Vukobratovic M, Hristic D, Stojiljkovic Z. Development of active anthropomorphic exoskeletons. Med Biol Eng. 1974; 12(1):66-80. [PMID:4465554] http://dx.doi.org/10.1007/BF02629836

17. Esquenazi A, Packel A. Robotic-assisted gait training and restoration. Am J Phys Med Rehabil. 2012;91(11 Suppl 3): S217-27, quiz S228-31. [PMID:23080038] http://dx.doi.org/10.1097/PHM.0b013e31826bce18

18. Zabaleta H, Bureau M, Eizmendi G, Olaiz E, Medina J, Perez M, editors. Exoskeleton design for functional rehabilitation in patients with neurological disorders and stroke. Proceedings of the IEEE 10th International Conference on Rehabilitation Robotics; 2007 Jun 13-15; Noordwijk, the Netherlands.

19. Zeilig G, Weingarden H, Zwecker M, Dudkiewicz I, Bloch A, Esquenazi A. Safety and tolerance of the ReWalk ${ }^{\mathrm{TM}}$ exoskeleton suit for ambulation by people with complete spinal 
cord injury: A pilot study. J Spinal Cord Med. 2012;35(2):

96-101. [PMID:22333043]

http://dx.doi.org/10.1179/2045772312Y.0000000003

20. Esquenazi A, Talaty M, Packel A, Saulino M. The ReWalk powered exoskeleton to restore ambulatory function to individuals with thoracic-level motor-complete spinal cord injury. Am J Phys Med Rehabil. 2012;91(11):911-21. [PMID:23085703] http://dx.doi.org/10.1097/PHM.0b013e318269d9a3

21. Dollar AM, Herr H. Lower extremity exoskeletons and active orthoses: Challenges and state-of-the-art. Robotics. IEEE Trans Robot. 2008;24(1):144-58. http://dx.doi.org/10.1109/TRO.2008.915453

22. Farris RJ, Quintero HA, Goldfarb M. Performance evaluation of a lower limb exoskeleton for stair ascent and descent with paraplegia. Proceedings of the 2012 Annual International Conference of the IEEE Engineering in Medicine and Biology Society; 2012 Aug 28-Sep 1; San Diego, CA.

23. Quintero HA, Farris RJ, Goldfarb M. A method for the autonomous control of lower limb exoskeletons for persons with paraplegia. J Med Device. 2012;6(4):0410031-36.

[PMID:23505407] http://dx.doi.org/10.1115/1.4007181

24. Spungen A, Asselin P, Fineberg D, Kornfeld S, Harel N. Exoskeletal-assisted walking for persons with motor-complete paraplegia. North Atlantic Treaty Organization (NATO), Research and Technology Organization, Human Factors and Medicine Panel, HFM-228 Symposium; 2013 Apr 15; Italy.

25. ReWalk-Rehabilitation [Internet]. Marlborough (MA): ReWalk Robotics; 2014 [cited 2014 May 29]. Available from: http://rewalk.com/products/rewalk-rehabilitation/

26. Sale P, Franceschini M, Waldner A, Hesse S. Use of the robot assisted gait therapy in rehabilitation of patients with stroke and spinal cord injury. Eur J Phys Rehabil Med. 2012;48(1):111-21. [PMID:22543557]

27. Goffer A, Tivon K, inventors. Gait-locomotor apparatus. United States patent US 7,153,242. 2003 May 24.

28. Shields RK, Schlechte J, Dudley-Javoroski S, Zwart BD, Clark SD, Grant SA, Mattiace VM. Bone mineral density after spinal cord injury: A reliable method for knee measurement. Arch Phys Med Rehabil. 2005;86(10):1969-73. [PMID:16213240] http://dx.doi.org/10.1016/j.apmr.2005.06.001

29. Fineberg DB, Asselin P, Harel NY, Agranova-Breyter I, Kornfeld SD, Bauman WA, Spungen AM. Vertical ground reaction force-based analysis of powered exoskeletonassisted walking in persons with motor-complete paraplegia. J Spinal Cord Med. 2013;36(4):313-21.

[PMID:23820147]

http://dx.doi.org/10.1179/2045772313Y.0000000126
30. Borg GA. Psychophysical bases of perceived exertion. Med Sci Sports Exerc. 1982;14(5):377-81. [PMID:7154893] http://dx.doi.org/10.1249/00005768-198205000-00012

31. Karvonen MJ, Kentala E, Mustala O. The effects of training on heart rate; a longitudinal study. Ann Med Exp Biol Fenn. 1957;35(3):307-15. [PMID:13470504]

32. Heyward V. Assessing cardiorespiratory fitness. In: Heyward VH, editor. Advanced fitness assessment \& exercise prescription. 6th ed. Champaign (IL): Human Kinetics; 2010.

33. Noreau L, Shephard RJ. Spinal cord injury, exercise and quality of life. Sports Med. 1995;20(4):226-50.

[PMID:8584848]

http://dx.doi.org/10.2165/00007256-199520040-00003

34. Whaley $\mathrm{MH}$, Brubaker PH, Otto RM, Armstrong LE. ACSM's guidelines for exercise testing and prescription. Philadelphia (PA): Lippincott Williams \& Wilkins; 2006.

35. Sedlock DA. Effect of exercise intensity on postexercise energy expenditure in women. Br J Sports Med. 1991; 25(1):38-40. [PMID:1913030] http://dx.doi.org/10.1136/bjsm.25.1.38

36. Mian OS, Thom JM, Ardigò LP, Morse CI, Narici MV, Minetti AE. Effect of a 12-month physical conditioning programme on the metabolic cost of walking in healthy older adults. Eur J Appl Physiol. 2007;100(5):499-505.

[PMID:16463043]

http://dx.doi.org/10.1007/s00421-006-0141-9

37. Pollock ML, Gaesser GA, Butcher JD, Després J-P, Dishman RK, Franklin BA, Garber CE. American College of Sports Medicine Position Stand: The recommended quantity and quality of exercise for developing and maintaining cardiorespiratory and muscular fitness, and flexibility in healthy adults. Med Sci Sports Exerc. 1998;30(6):975-91. [PMID:9624661] http://dx.doi.org/10.1097/00005768-199806000-00032

38. Bauman WA, Spungen AM. Carbohydrate and lipid metabolism in chronic spinal cord injury. J Spinal Cord Med. 2001;24(4):266-77. [PMID:11944785]

39. Spungen AM, Adkins RH, Stewart CA, Wang J, Pierson RN Jr, Waters RL, Bauman WA. Factors influencing body composition in persons with spinal cord injury: A crosssectional study. J Appl Physiol. 2003;95(6):2398-2407. [PMID:12909613] http://dx.doi.org/10.1152/japplphysiol.00729.2002

40. Hicks AL, Martin KA, Ditor DS, Latimer AE, Craven C, Bugaresti J, McCartney N. Long-term exercise training in persons with spinal cord injury: Effects on strength, arm ergometry performance and psychological well-being. Spinal Cord. 2003;41(1):34-43. [PMID:12494319] http://dx.doi.org/10.1038/sj.sc.3101389

41. Washburn RA, Figoni SF. High density lipoprotein cholesterol in individuals with spinal cord injury: The potential role of physical activity. Spinal Cord. 1999;37(10):685-95. 


\section{[PMID:10557124]}

http://dx.doi.org/10.1038/sj.sc.3100917

42. Ditor DS, Latimer AE, Ginis KA, Arbour KP, McCartney N, Hicks AL. Maintenance of exercise participation in individuals with spinal cord injury: Effects on quality of life, stress and pain. Spinal Cord. 2003;41(8):446-50.

[PMID:12883542]

http://dx.doi.org/10.1038/sj.sc.3101487

43. Nash MS, Gater DR. Exercise to reduce obesity in SCI. Top Spinal Cord Inj Rehabil. 2007;12(4):76-93. http://dx.doi.org/10.1310/sci1204-76

44. Spungen A, Asselin P, Fineberg D, Harel N, Kornfeld S, Bauman W. Beneficial changes in body composition after exoskeletal-assisted walking: Implications for improved metabolic function. Top Spinal Cord Inj Rehabil. 2013; 19(5):8-9.

45. Winchester PK, Carollo JJ, Parekh RN, Lutz LM, Aston JW Jr. A comparison of paraplegic gait performance using two types of reciprocating gait orthoses. Prosthet Orthot Int. 1993;17(2):101-106. [PMID:8233765]

46. Bernardi M, Canale I, Castellano V, Di Filippo L, Felici F, Marchetti M. The efficiency of walking of paraplegic patients using a reciprocating gait orthosis. Paraplegia. 1995;33(7):409-15. [PMID:7478731] http://dx.doi.org/10.1038/sc.1995.91

47. Felici F, Bernardi M, Radio A, Marchettoni P, Castellano V, Macaluso A. Rehabilitation of walking for paraplegic patients by means of a treadmill. Spinal Cord. 1997;35(6): 383-85. [PMID:9194261] http://dx.doi.org/10.1038/sj.sc.3100403

48. IJzerman MJ, Baardman G, van 't Hof MA, Boom HB, Hermens HJ, Veltink PH. Validity and reproducibility of crutch force and heart rate measurements to assess energy expenditure of paraplegic gait. Arch Phys Med Rehabil. 1999;80(9):1017-23. [PMID:10489002] http://dx.doi.org/10.1016/S0003-9993(99)90054-0

49. Merati G, Sarchi P, Ferrarin M, Pedotti A, Veicsteinas A. Paraplegic adaptation to assisted-walking: Energy expenditure during wheelchair versus orthosis use. Spinal Cord. 2000;38(1):37-44. [PMID:10762196]

http://dx.doi.org/10.1038/sj.sc.3100946
50. Huang CT, Kuhlemeier KV, Moore NB, Fine PR. Energy cost of ambulation in paraplegic patients using Craig-Scott braces. Arch Phys Med Rehabil. 1979;60(12):595-600. [PMID:518268]

51. Astrand PO, Saltin B. Maximal oxygen uptake and heart rate in various types of muscular activity. J Appl Physiol. 1961;16:977-81. [PMID:13863012]

52. Bergh U, Kanstrup IL, Ekblom B. Maximal oxygen uptake during exercise with various combinations of arm and leg work. J Appl Physiol. 1976;41(2):191-96. [PMID:956101]

53. Vokac Z, Bell H, Bautz-Holter E, Rodahl K. Oxygen uptake/heart rate relationship in leg and arm exercise, sitting and standing. J Appl Physiol. 1975;39(1):54-59.

54. Forrest G, Sisto S, Asselin P, Mores J, Bond Q, LaFountaine M, Harkema S. Locomotor training with incremental changes in velocity: Muscle and metabolic responses. Top Spinal Cord Inj Rehabil. 2008;14(1):16-22.

http://dx.doi.org/10.1310/sci1401-16

Submitted for publication February 26, 2014. Accepted in revised form December 22, 2014.

This article and any supplementary material should be cited as follows:

Asselin P, Knezevic S, Kornfeld S, Cirnigliaro C, Agranova-Breyter I, Bauman WA, Spungen AM. Heart rate and oxygen demand of powered exoskeleton-assisted walking in persons with paraplegia. J Rehabil Res Dev. 2015;52(2):147-58.

http://dx.doi.org/10.1682/JRRD.2014.02.0060

ResearcherID: Pierre Asselin, MS: D-2814-2015; Irina Agranova-Breyter, PT: D-3122-2015; William A. Bauman, MD: D-2871-2015; Steven Knezevic, MS: D-28212015; Christopher Cirnigliaro, MS: D-3708-2015; Stephen Kornfeld, DO: E-1315-2015

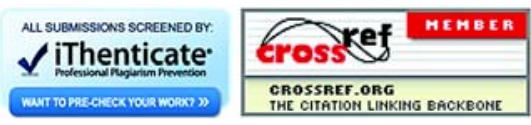

